Mr Igor S. Simić, kapetan I klase, dipl. inž. VP 4522 Batajnica

Dr Aleksa J. Zejak, docent, dipl. inž. Institut IMTEL, Novi Beograd

\section{SAW KOMPONENTE I NJIHOVE PRIMENE U OBRADI SIGNALA}

UDC: $534.87: 621.391$

Rezime:

SAW (Surface Acoustic Wave) komponente, ili komponente sa površinskim akustickim talasom, imaju široku primenu u analognoj obradi signala. Razlicitim tipovima SAW komponenti mogu se postići mnoge funkcije u obradi signala. $U$ ovom radu prikazane su najčešce primene $S A W$ komponenti u komunikacionim, radarskim $i$ sonarskim uređajima, kao i sistemima za protivelektronsku borbu.

Ključne reči: SAW komponente, linija za kašnjenje, čirp, konvolver, korelator, kompresija impulsa, sintezator frekvencije, prilagodeni filter.

\title{
SAW DEVICES AND ITS SIGNAL PROCESSING APPLICATIONS
}

\section{Summary:}

SAW or surface acoustic wave devices have a wide application in analog signal processing. Many different signal processing functions can be achieved by different $S A W$ devices. In this paper we described the most significant use of SAW devices in communication, radar and sonar equipment as well as in electronic warfare systems.

Key words: SAW devices, delay line, chirp, convolver, correlator, pulse compression, frequency generator, matched filter.

\section{Uvod}

Komponente SAW (Surface Acoustic Wave) ili komponente sa površinskim akustičkim talasom, imaju široku primenu u analognoj obradi signala. Različitim tipovima ovih komponenti mogu se projektovati: filteri (sa fiksnim i promenljivim propusnim opsegom), kompresioni filteri, linije za kašnjenje (sa fiksnim i promenljivim kašnjenjem), korelatori, konvolveri, Furijeovi transformatori, prilagođeni filteri, generatori talasnih obli$\mathrm{ka}$, analogne memorije, diskriminatori i sl.
Glavne prednosti SAW komponenti jesu: mogućnost obrade signala u realnom vremenu, male dimenzije i jednostavnost, a nedostatak predstavlja ograničen dinamički opseg.

Iako digitalna obrada signala omogućava fleksibilnost i programabilnost veću od bilo koje druge tehnologije, SAW komponente još uvek nalaze svoju primenu u radarskim i sonarskim sistemima, komunikacijama sa prenosom u proširenom spektru, kao i prijemnicima za elektronski rat. 


\section{Princip rada SAW komponenti}

Radio-frekventni signal može se pretvoriti u akustički talas na koji je moguće uticati promenom uslova propagacije na površini piezoelektričnog supstrata. Obrađeni analogni signal dobija se ponovnom konverzijom akustičkog $\mathrm{u}$ električni signal. Ovaj postupak nalazi se $u$ osnovi načina rada komponenti sa površinskim akustičkim talasom. Drugim rečima, ulazna elektromagnetska energija pretvara se u mehaničku, odnosno u akustički talas koji nastaje zbog rastezanja i skupljanja piezoelektrika, a zatim se, promenom uslova prostiranja akustičkih talasa, menja faza i amplituda signala, unosi kašnjenje i na kraju se ponovo akustički talas (mehanička energija) piezoelektrikom „vraća“ u električni signal.

Akustički talasi su locirani na površini supstrata i udaljavanjem od nje intenzivno slabe. $U$ tome je i osnovna tehnološka razlika SAW komponenti i kristala kvarca, u kome se akustički talasi prostorno šire. Brzina prostiranja akustič-

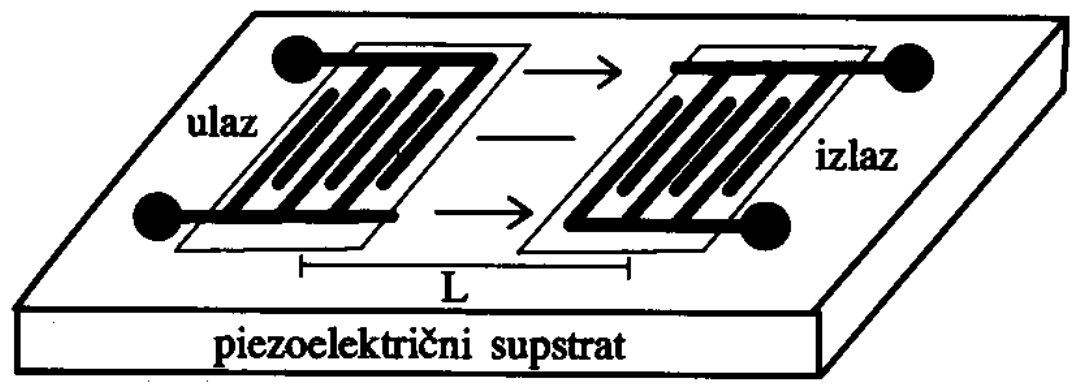

Sl. 1-Prikaz jednostavne SAW linije za kašnjenje

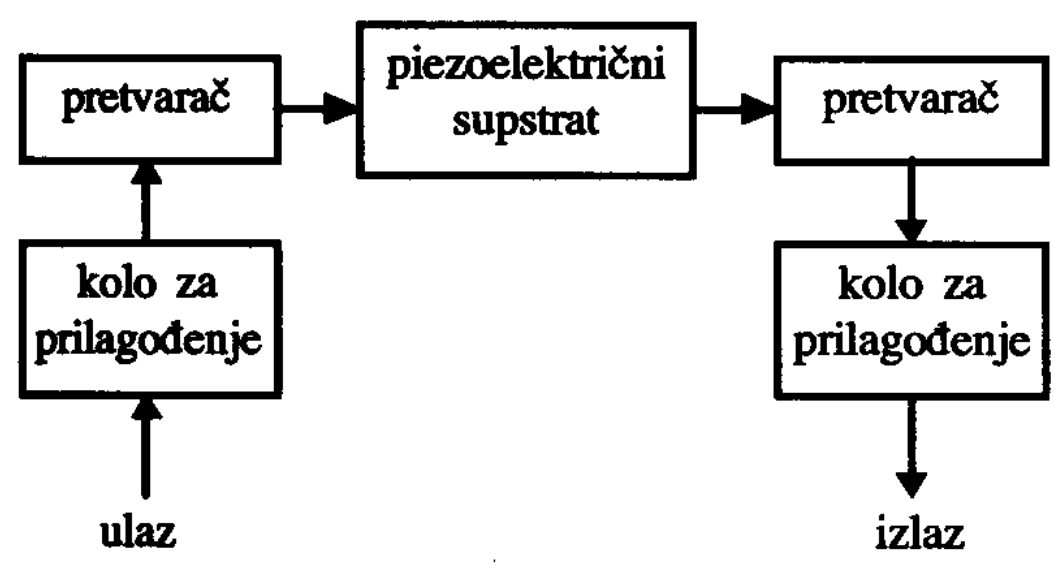

Sl. 2 - Osnovni elementi SAW komponente kih talasa na površini piezoelektričnog materijala praktično ne zavisi od frekvencije i približno iznosi $3000 \mathrm{~m} / \mathrm{s}$ (zavisno od tipa supstrata iznosi od 1680 do 6170 $\mathrm{m} / \mathrm{s}$ ). To je $\sim 10^{5}$ puta manje od brzine prostiranja elektromagnetskog talasa $u$ slobodnom prostoru, pa omogućava da komponente za obradu signala budu manjih dimenzija. Na slici 2 prikazana je opšta blok-šema SAW komponente.

Da se talasi ne bi reflektovali na rubovima supstrata, postavljaju se posebno naneseni slojevi apsorpcionog materijala. Ovaj problem se na drugi način rešava zakošenjem bočnih ivica supstrata.

Materijali koji se najčešće koriste za izradu supstrata su [1,2]: litijum-niobat $\left(\mathrm{LiNbO}_{3}\right)$, kvarc $\left(\mathrm{SiO}_{2}\right), \mathrm{Bi}_{12} \mathrm{GeO}_{20}$ i Li$\mathrm{TaO}_{3}$. Izbor materijala uslovljen je nizom faktora. Tako su, na primer, komponente sa kvarcnim supstratom najmanje osetljive na promene temperature, $\mathrm{LiNbO}_{3}$ ima najveći koeficijent elektro-akustičke konverzije, a $\mathrm{Bi}_{12} \mathrm{GeO}_{20}$ ima najmanju brzinu prostiranja akustičkih talasa (1650 $\mathrm{m} / \mathrm{s}$ ).

Za generisanje i prijem površinskih akustičkih signala koristi se pretvarač (transducer). Karakteristike SAW komponente najvećim delom su određene svojstvima pretvarača. Predajni i prijemni pretvarači površinskih akustičkih talasa najčeće se proizvode u obliku „češlja“ koji se u vidu metalnih elektroda nanosi na glatki supstrat. Osnovne veličine kod pretvarača su: $d$ - rastojanje između susednih „zubaca“, $N$ - broj traka u češlju i $A$ - konstanta elektro-akustičke konverzije.

Pritisak koji se dobija u tački na površini supstrata, na rastojanju $\mathrm{x}$ od pretvarača, kada se elektrode pretvarača pobuđuju signalom $\mathrm{u}=\mathrm{U} \cos (\omega \mathrm{t})$, jeste [1]: 
$\left.\mathrm{p}(\mathrm{t}, \mathrm{x})=2 \mathrm{NAU} \sin \left(\frac{\pi \omega}{2 \omega_{0}}\right) \frac{\sin \left(\mathrm{N} \pi \omega / \omega_{0}\right.}{\mathrm{N} \sin \left(\pi \omega / \omega_{0}\right.}\right) \sin \left(\omega \mathrm{t}-\frac{\pi \mathrm{x} \omega}{\mathrm{d} \omega_{0}}\right)$,

gde je $\omega_{0}=2 \pi \mathrm{f}_{0}=\pi \mathrm{v} / \mathrm{d}$ sopstvena frekvencija pretvarača.

Napon na izlazu prijemnog pretvarača sa $M$ traka u češlju i elektro-akustičkom konstantom B dat je izrazom [1]:

$\mathrm{u}_{\mathrm{i}}=\mathrm{U}_{\mathrm{i}} \cos (\omega \mathrm{t}-\psi)$,

gde je:

$\mathrm{U}_{\mathrm{i}}=4 \mathrm{NMABU} \sin ^{2}\left(\frac{\pi \omega}{2 \omega_{0}}\right) \frac{\sin \left(\mathrm{N} \pi \omega / \omega_{0}\right) \sin \left(\mathrm{M} \pi \omega / \omega_{0}\right)}{\mathrm{NM} \sin \left(\pi \omega / \omega_{0}\right)}$,

a faza $\psi=\frac{\pi \times \omega}{\mathrm{d} \omega_{0}}$.

Amplitudsko-frekvencijska karakteristika SAW komponente sa dva pretvarača i $\mathrm{N}$ traka u svakom od njih je:

$|\mathrm{H}(\omega)|=\frac{\mathrm{U}_{\mathrm{i}}}{\mathrm{U}_{\mathrm{u}}}=\left[\sin \left(\frac{\pi}{2} \frac{\omega}{\omega_{0}}\right) \frac{\sin \left(\mathrm{N} \pi \omega / \omega_{0}\right)}{\mathrm{N} \sin \left(\pi \omega / \omega_{0}\right)}\right]^{2}$.

Zbog neprilagođenosti impedansi na strani izvora i na strani opterećenja, uneseno slabljenje se povećava, pa se SAW komponenti dodaju kola za prilagođenje. U impedansi pretvarača dominira statička kapacitivnost, tako da se prilagođenje na strani izvora, odnosno opterećenja, obavlja pomoću odgovarajućeg induktiviteta.

Tabela 1 Približne vrednosti maksimalnog kašnjenja SAW linije za kašnjenje

\begin{tabular}{|c|c|}
\hline $\begin{array}{c}\text { Frekvencijski opseg } \\
(\mathrm{MHz})\end{array}$ & Kašnjenje $(\mu \mathrm{s})$ \\
\hline 10 & $80-100$ \\
\hline 20 & $60-80$ \\
\hline 50 & $45-60$ \\
\hline 100 & $20-30$ \\
\hline 200 & $5-15$ \\
\hline 500 & $2-5$ \\
\hline 1000 & $0,4-0,6$ \\
\hline
\end{tabular}

Zahvaljujući tehnologiji elektronske litografije, razvoj SAW komponenti omogućio je njihovu primenu u mikrotalasnom frekvencijskom opsegu $(<2 \mathrm{GHz})$. Poboljšnja u oblasti materijala dovela su do znatno manjih unesenih gubitaka $(<30$ dB) i povećanja frekvencijskog opsega $(1 \mathrm{GHz})$. Maksimalna kašnjenja, koja se mogu ostvariti SAW linijama za kašnjenje, prikazana su u tabeli 1 .

\section{Linije za kašnjenje}

Linija za kašnjenje je filter čije je kašnjenje funkcija ulazne frekvencije. Karakteristika linearne disperzivne linije za kašnjenje, ili čirp-filtera, prikazana je na slici 3.

Postoje dva osnovna pristupa u projektovanju SAW linija za kašnjenje. Prvi 
a)

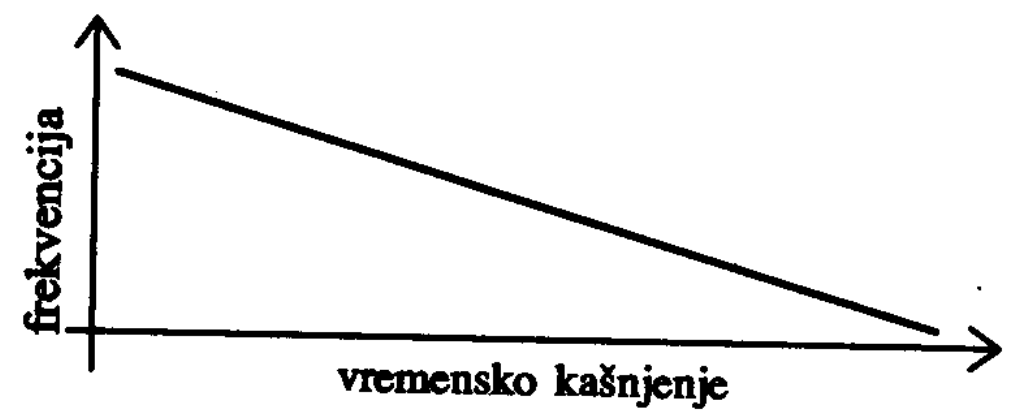

b)

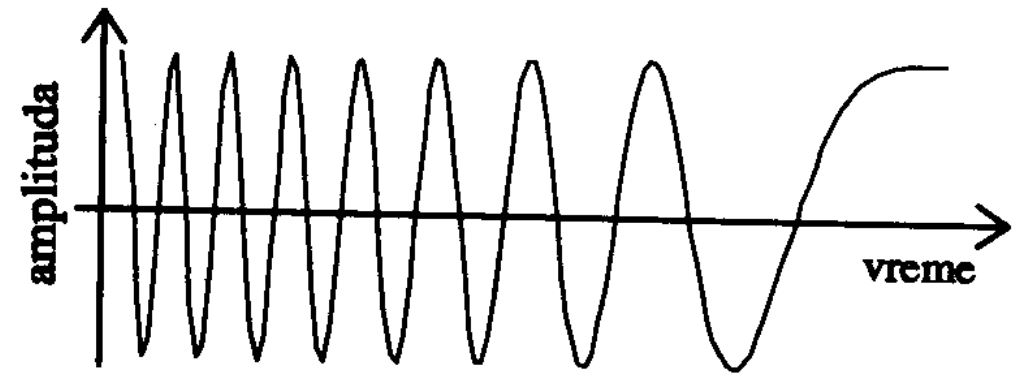

Sl. 3 - Karakteristika linearne disperzivne linije za kašnjenje: a - odnos trenutne frekvencije $i$ kašnjenja, b-impulsni odziv filtera značajnije potiskivanje bočnih snopova kada se očekuju varijacije temperature [3]. Treba napomenuti da je na bazi struktura RAC razvijen filter IMCON SAW [4] za kompresiju impulsa koji ima veliki TB proizvod, uz dobru linearnost i malu osetljivost na mehaničke promene.

Linije za kašnjenje i čirp-filter nalaze primenu u mnogim sklopovima za obradu signala. Najčešća primena je u radarskim sistemima za kompresijom impulsa čirpsignalom. Generisanje signala pri predaji obavlja se impulsnom pobudom SAW linije za kašnjenje (ekspander). Drugom linijom za kašnjenje (cirp-filterom) u prijemniku obavlja se kompresija signala a)

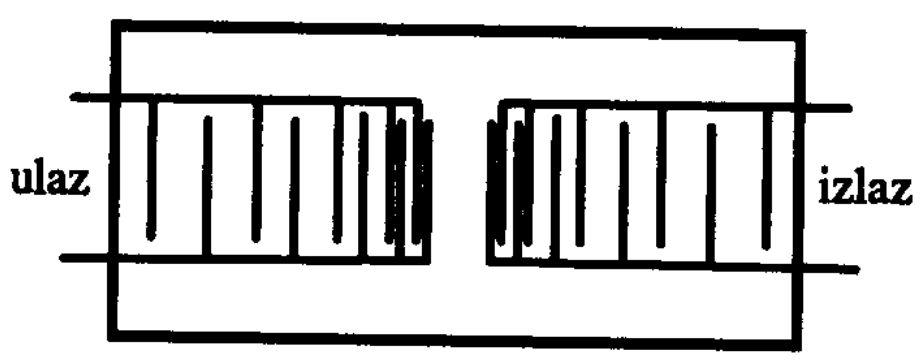

b)

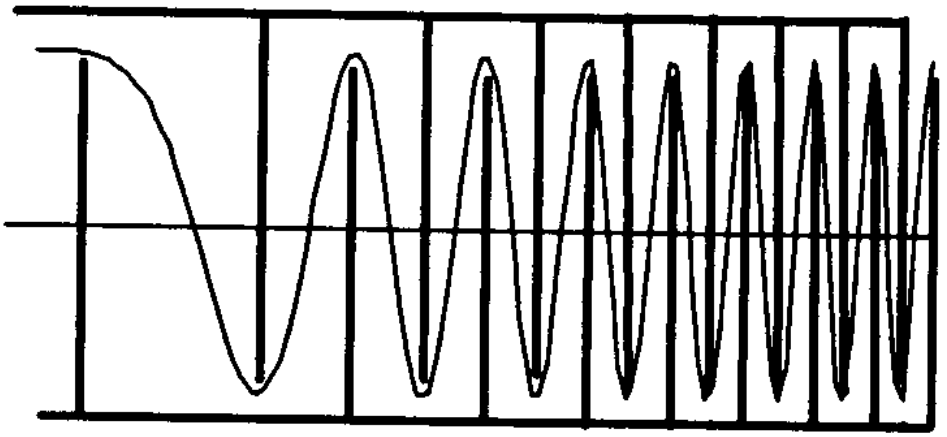

Sl. 4 - Direktna sinteza SAW linije za kašnjenje:

$a$ - oblik SAW komponente, $b$ - generisanje linearnog cirpa elektrodama pretvarača

način podrazumeva da akustički talas putuje direktno od ulaznog do izlaznog pretvarača (IDT Inter - Digital Transducers), što je prikazano na slici 4 .

Kod drugog načina, na putu akustičkog talasa nalaze se reflektori kojima se utiče na fazu reflektovanih talasa (RAC Reflective Array Compressor), što je prikazano na slici 5 .

Primena SAW linija za kašnjenje (čirp-kompresioni filter) sa refleksijom zvučnog talasa (RAC) omogućava veće vrednosti TB proizvoda. Međutim, ove strukture su manje temperaturno i mehanički stabilne, pa nije moguće postići reflektovanog od cilja, što je prikazano na slici 6 . U osnovi kompresije impulsa

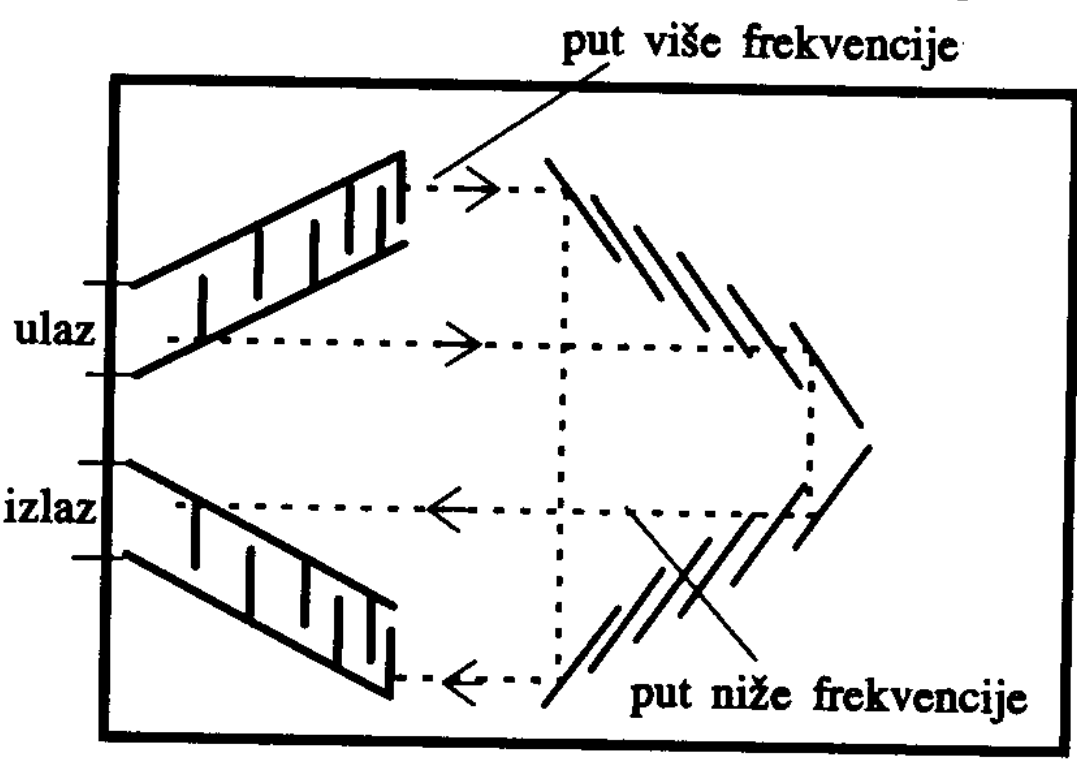

Sl. 5 - SAW čirp-linija za kašnjenje sa refleksijom zvučnog talasa 


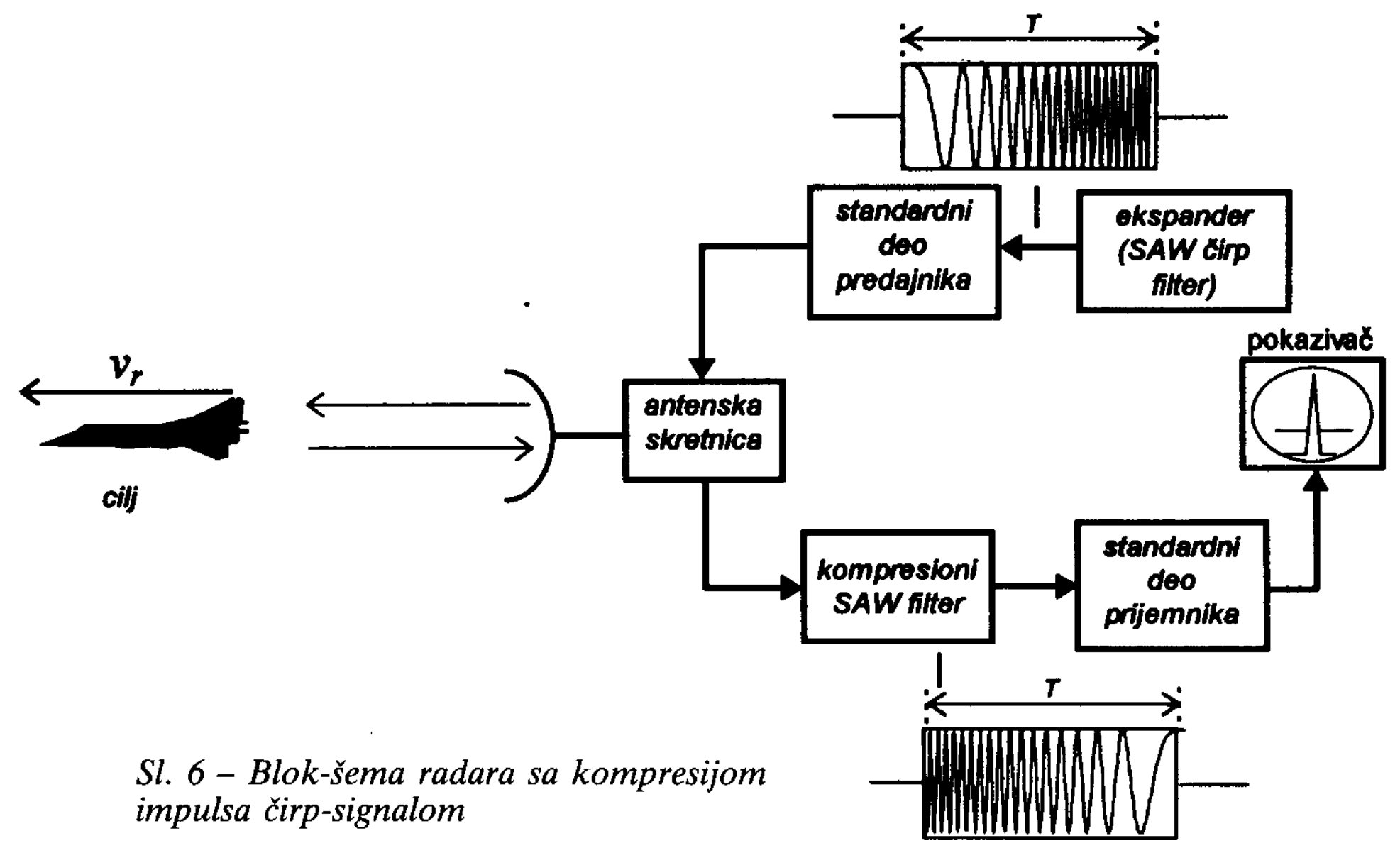

jeste postupak unutarimpulsne modulacije signala. Termin kompresija impulsa potiče od funkcije prijemnika, koji čirpsignal, reflektovan od cilja, pretvara $u$ uski impuls, na svom izlazu, uz očuvanje ukupne energije.

Prilagođeni filter za složene radarske signale jeste istovremeno i kompresioni filter, koji široki impuls na ulazu trajanja T pretvara u uski impuls na izlazu. Vršna snaga ulaznog impulsa je mnogo manja od vršne snage izlaznog impulsa, ali im je ukupna energija jednaka.

Linije za kašnjenje koriste se i za izradu analognih Furijeovih transformatora. Množenjem ulaznog signala sa čirpsignalom, zatim konvolucijom sa čirpom (propuštanjem kroz čirp-filter) i množenjem dobijenog signala sa čirpom dobija se Furijeova transformacija signala. Furijeova transformacija dobijena na taj način zove se i čirp-transformacija, a sklop kojim se to postiže u literaturi poznat je kao kompresivni ili mikrosken prijemnik. Ovaj tip prijemnika, zbog osobine da $\mathrm{u}$ kratkom intervalu odredi Furijeovu transformaciju širokopojasnog signala, nalazi široku primenu u sistemima za protivelektronsku borbu. Na slici 7 prikazana je blok-šema kompresivnog prijemnika.

Čirp-tranformacija može se posmatrati i kao relacija inverzne Furijeove transformacije, tako da se modifikacijom prethodne blok-šeme dobija generator talasnih oblika. Dovođenjem Furijeove transformacije željenog signala na ulaz sklopa, na izlazu se dobija inverzna Furijeova transformacija. Za sintezu sinusnog signala frekvencije f, čija se Furijeova transformacija sastoji od dve spektralne linije na frekvencijama $\pm f$ koje su međusobno razdvojene $2 \mathrm{f}$, potreban ulaz $\mathrm{u}$ sklop predstavljaju dva impulsa vremen-

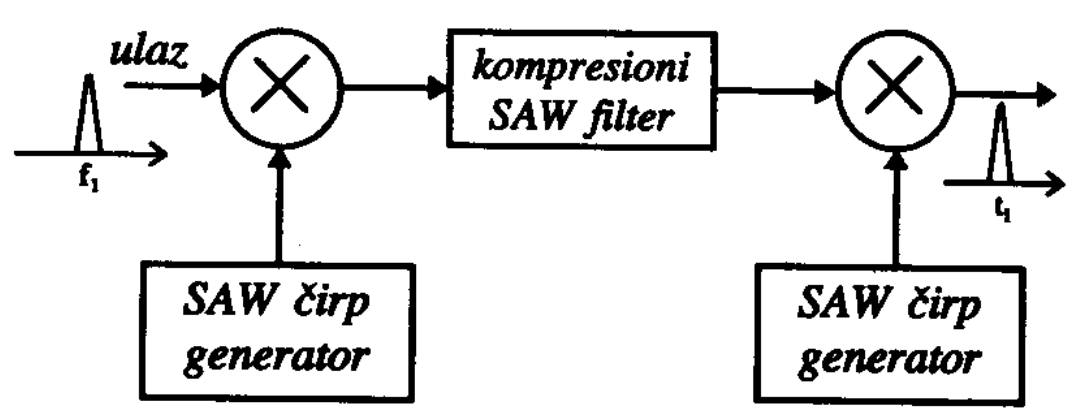

Sl. 7 - Blok-šema kompresivnog prijemnika 
ski razmaknuta za $2 \mathrm{f} / \mathrm{k}$. Blok-šema sintezatora frekvencije, primenom čirp-filtera, SAW prikazana je na slici 8 .

Promenom međusobnog kašnjenja među ulaznim impulsima frekvencija izlaznog signala može se menjati. Ova tehnika je primenjena pri generisanju koherentnih signala za frekvencijsko skakanje [3,5]. Na slici 9 prikazana je blok-šema sintezatora frekvencije za signale sa frekvencijskim skakanjem.

Ako su $r_{1}(t)$ i $R_{1}(f)$, kao i $r_{2}(t)$ i $R_{2}(f)$ Furijeovi transformacioni parovi, tada je, prema teoremi konvolucije,

$$
\int_{-\infty}^{\infty} r_{1}(\tau) r_{2}(t-\tau) d \tau \text { i } R_{1}(f) R_{2}(f)
$$

takođe, Furijeov transformacioni par. Ova teorema pokazuje da je konvoluciju moguće realizovati u vremenskom ili frekvencijskom domenu. Računanjem inverzne Furijeove transformacije proizvoda Furijeovih transformacija dva signala do- bija se konvolucija u frekvencijskom domenu.

Ovom tehnikom, pomoću SAW čirpfiltera, projektuju se filteri sa promenljivim propusnim opsegom, kao i druge vrste programabilnih analognih filtera. $U$ radarskoj tehnici se programabilnim filterima postiže prilagođeno filtriranje za proizvoljan skup predajnih signala. Dodatna prednost jeste da se programabilnim korelatorima može postići kompresija radarskog impulsa bez neželjenih bočnih snopova [6]. Na slici 10 prikazana je blok-šema programabilnog filtera (programabilnog konvolvera) koja je ostvarena primenom teoreme o konvoluciji.

Razvojem tehnologije SAW komponenti prethodna šema za konvoluciju zamenjena je SAW komponentama projektovanim za konvoluciju ulaznog i proizvoljnog referentnog signala.

Promenljiva linija za kašnjenje je još jedna funkcija $u$ analognoj obradi signala koja se može ostvariti primenom SAW

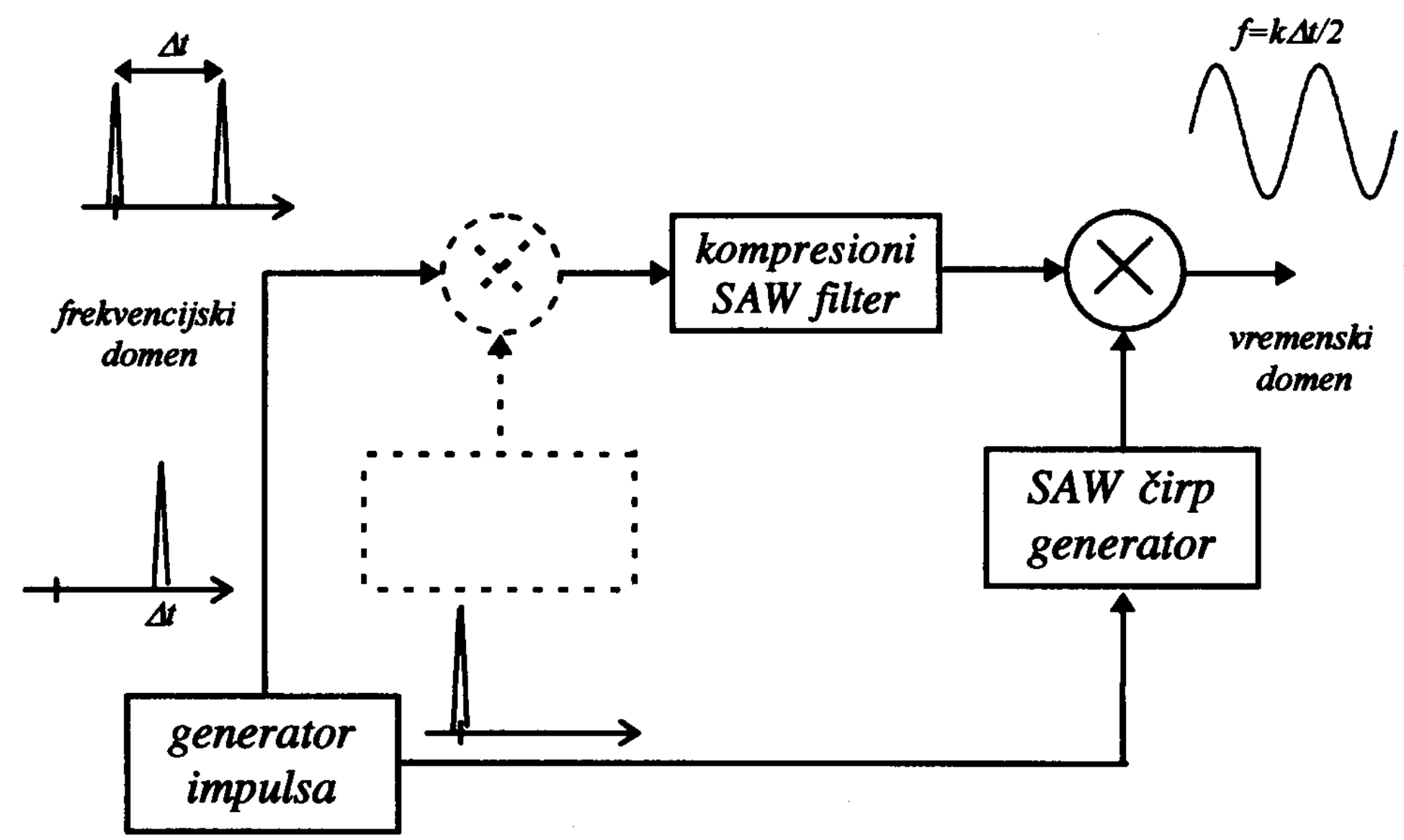

Sl. 8 - Sintezator frekvencija pomoću inverzne SAW cirp-transformacije 


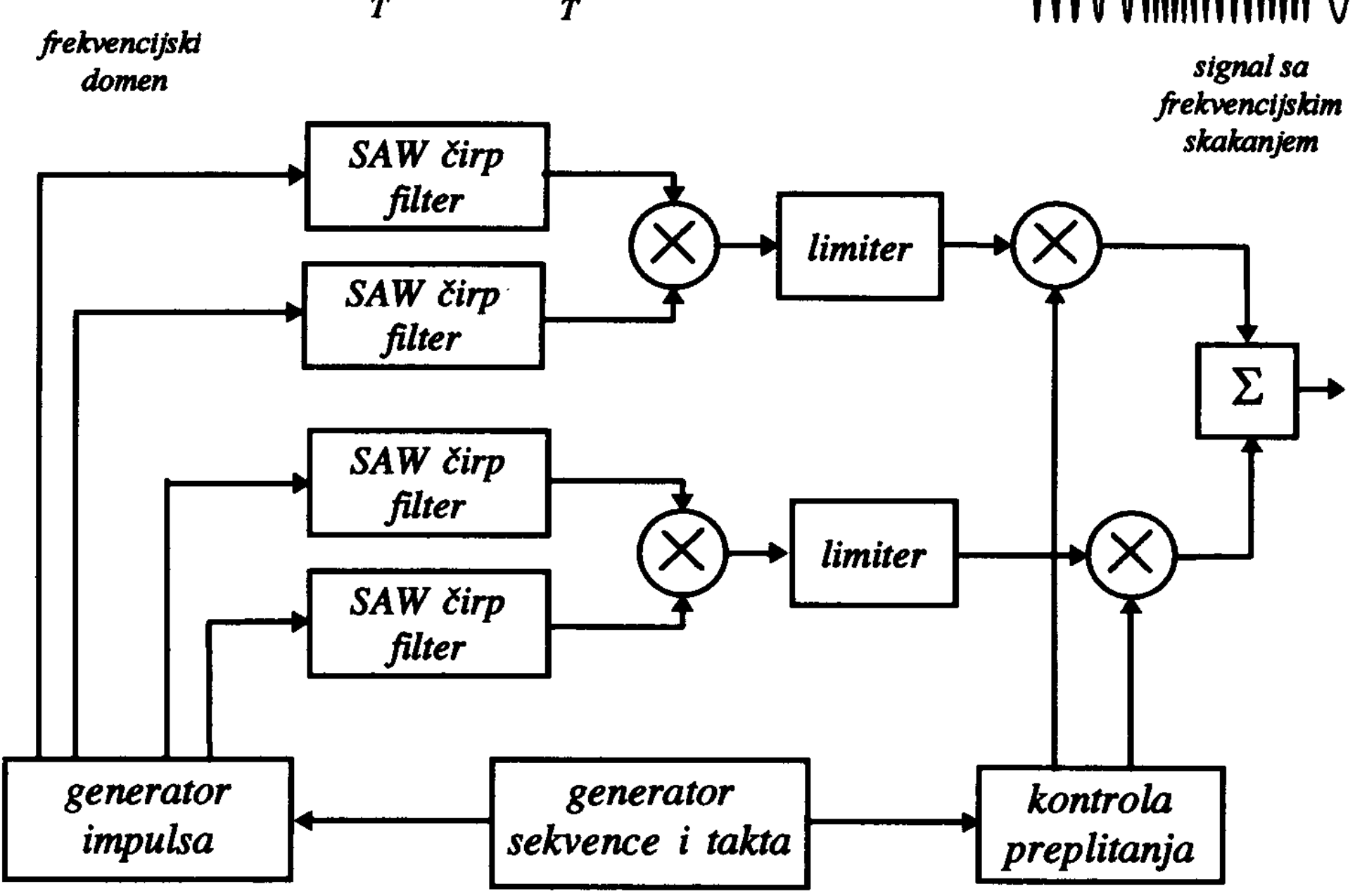

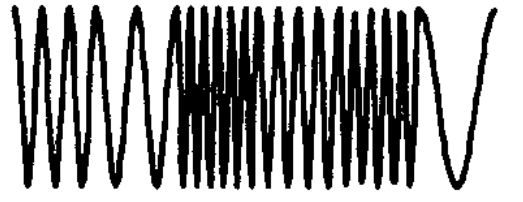

frekvencijskim skakanjem

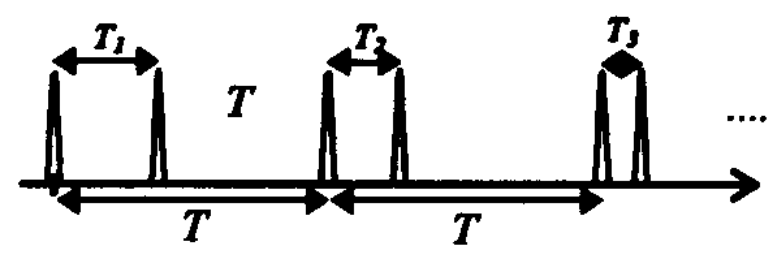

frekvencijsk

limiter

Sl. 9 - Sintezator frekvencija za signale sa frekvencijskim skakanjem

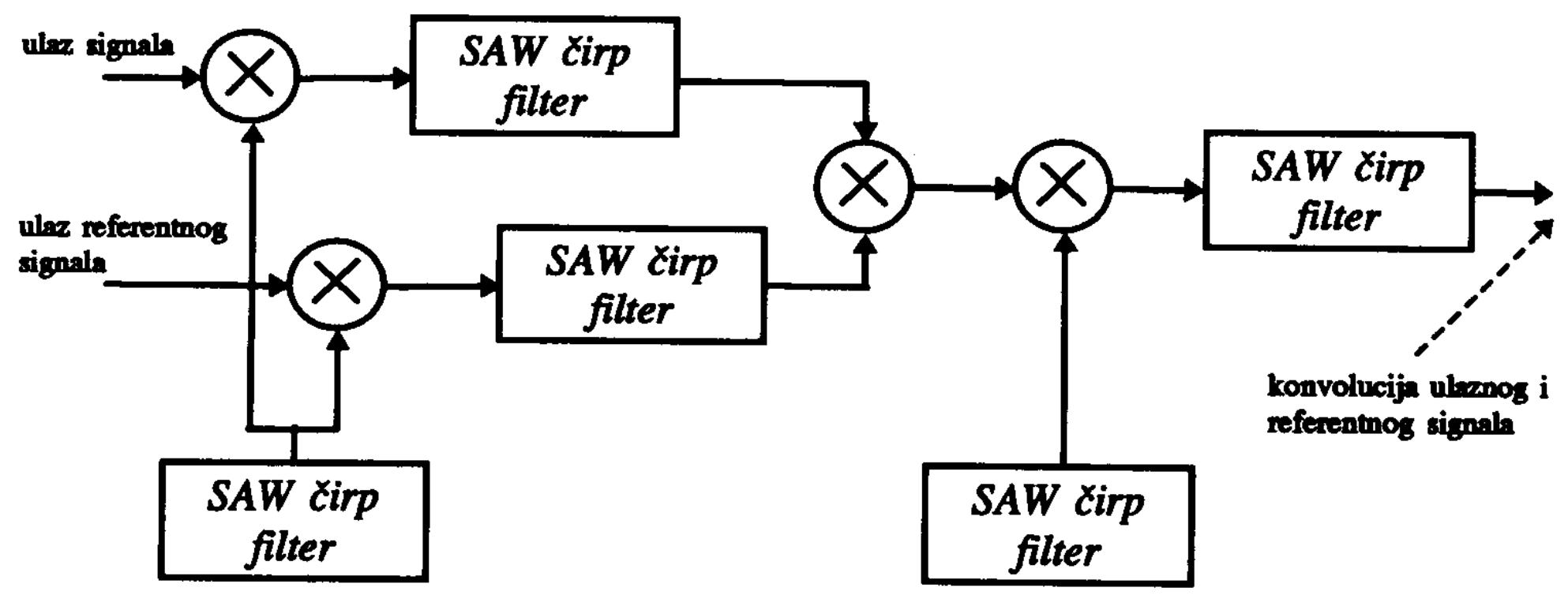

Sl. 10 - Blok-šema programabilnog filtera

komponenti. Na slici 11 prikazana je blok-šema promenljive linije za kašnjenje. Precizno vreme kašnjenja izlaznog impulsa određeno je frekvencijom signala iz naponom kontrolisanog oscilatora $\mathrm{f} i$ strminom promene trenutne frekvencije impulsnog odziva čirp-filtera $\mathrm{k}$ :

$$
\tau=\tau_{0}+\frac{2 \pi f}{k}
$$




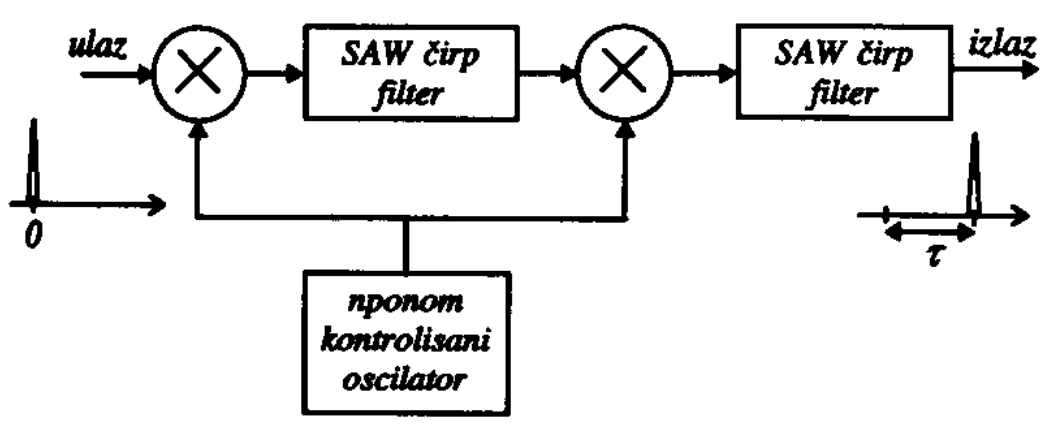

Sl. 11 - Blok-šema promenljive linije za kašnjenje

gde je $\tau_{0}$ fiksno kašnjenje koje postoji nezavisno od frekvencije.

\section{Fiksni korelatori i konvolveri}

Čirp-filter SAW (čirp prilagođeni filter) jeste komponenta koja se koristi za detekciju linearno frekvencijski modulisanih signala. Linija za kašnjenje je fiksni korelator za linearni čirp-signal. Jedna od važnih prednosti SAW komponenti jeste da signali mogu biti odabirani duž puta prostiranja akustičkog talasa. Svaki odbirak može se akustički ili elektronski ponderisati odgovarajućom amplitudom ili fazom, što predstavlja direktnu realizaciju transverzalnog filtera. Na slici 12 prikazana je jedna od mogućih struktura ponderisane linije za kašnjenje. Ovakve strukture pogodne su za realizaciju prilagođenih i razdešenih filtera za fazno modulisane signale.

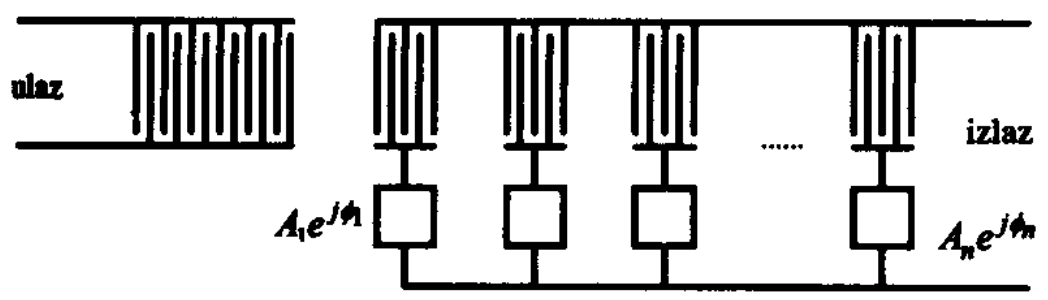

Sl. 12 - Linija za kašnjenje sa faznim i amplitudskim ponderisanjem

Ako se postavi da $\mathrm{A}_{\mathrm{n}} \mathrm{e}^{\mathrm{j} \phi_{\mathrm{n}}}$ ima vrednosti -1 i 1 , može se generisati bifazno kodovan signal, odnosno formirati prilagođeni filter za binarni kod, kao što je prikazano na slici 13 .
Osnovni nedostatak fiksnih korelatora jeste da se sekvenca ili signal na koji je korelator prilagođen može menjati samo pravljenjem nove komponente.

\section{Programabilni korelatori i konvolveri}

Područje upotrebe SAW komponenti prošireno je formiranjem programabilnih korelatora i konvolvera. Postoje dva osnovna načina kojima se to postiže. Prvi podrazumeva promenu impulsnog odziva SAW komponente dodavanjem jednostavnih prekidačkih sklopova i manipulisanjem pojedinačnim težinama. Ovaj metod pogodan je za programabilne prilagođene filtere i generatore digitalnih signala $[2,7]$.

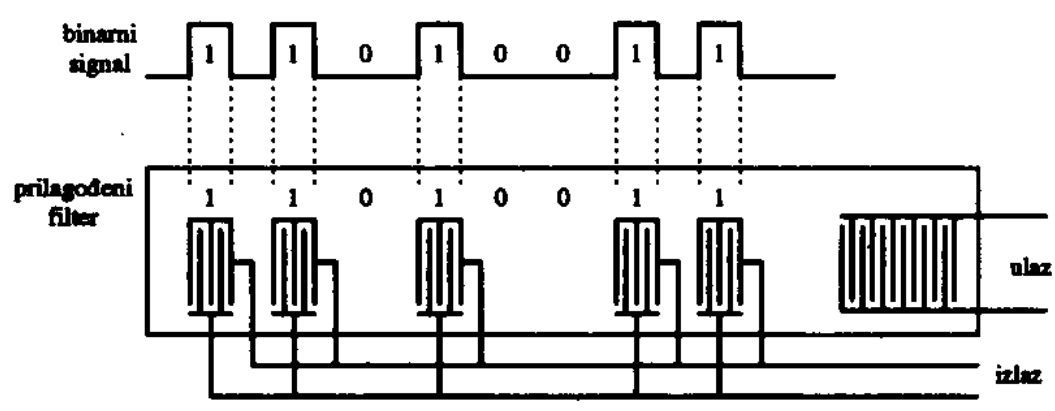

Sl. 13 - Prilagodeni SAW filter za binarni signal

Drugi način koristi nelinearnu interakciju između ulaznog i referentnog signala kako bi se dobila njihova konvolucija. Oblik ovog tipa komponente prikazan je na slici 14a.

Konvolveri se sastoje od supstrata na kojem su dva ulazna pretvarača koji konvertuju ulazne signale $\xi_{\mathrm{a}}(\mathrm{t}) \mathrm{i} \xi_{\mathrm{b}}(\mathrm{t}) \mathrm{u}$ odgovarajuće površinske akustičke talase. Talasi se prostiru u suprotnim smerovima, a iznad površine supstrata nalazi se silicijum, kao što je prikazano na slici $14 b$. Oba signala se propuštaju u vremenskom intervalu $\mathrm{T}$. U prostoru ispod silicijuma akusticki talasi se međusobno pre- 


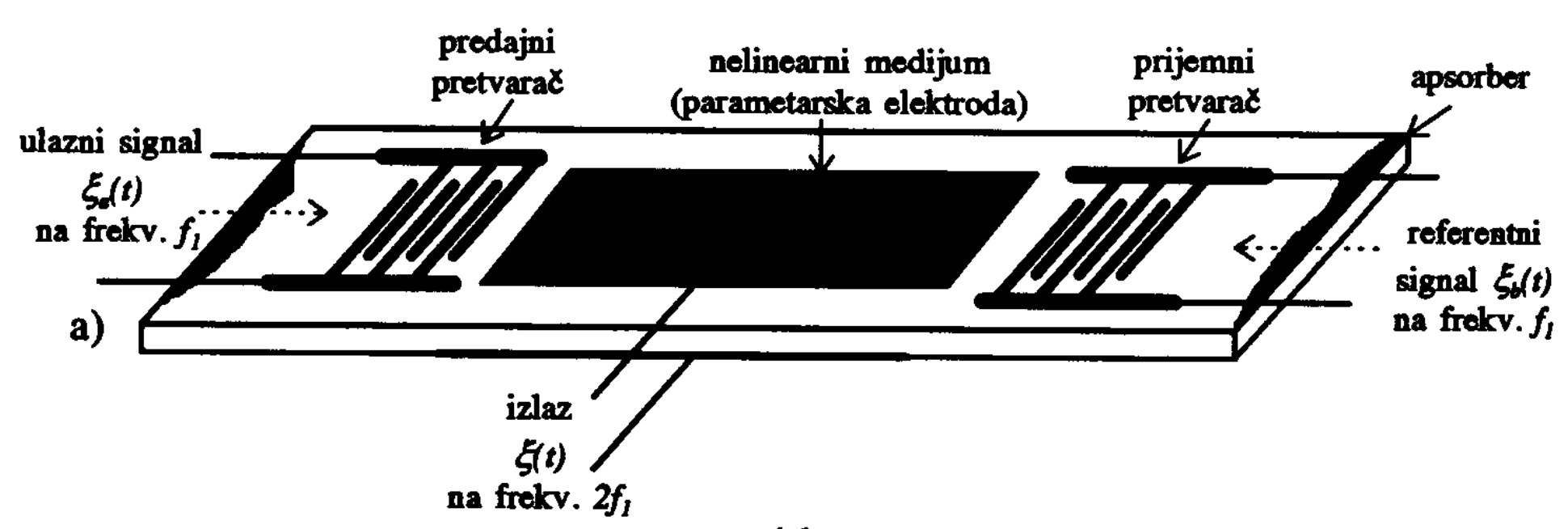

na frekv. $2 f_{1}$

b)

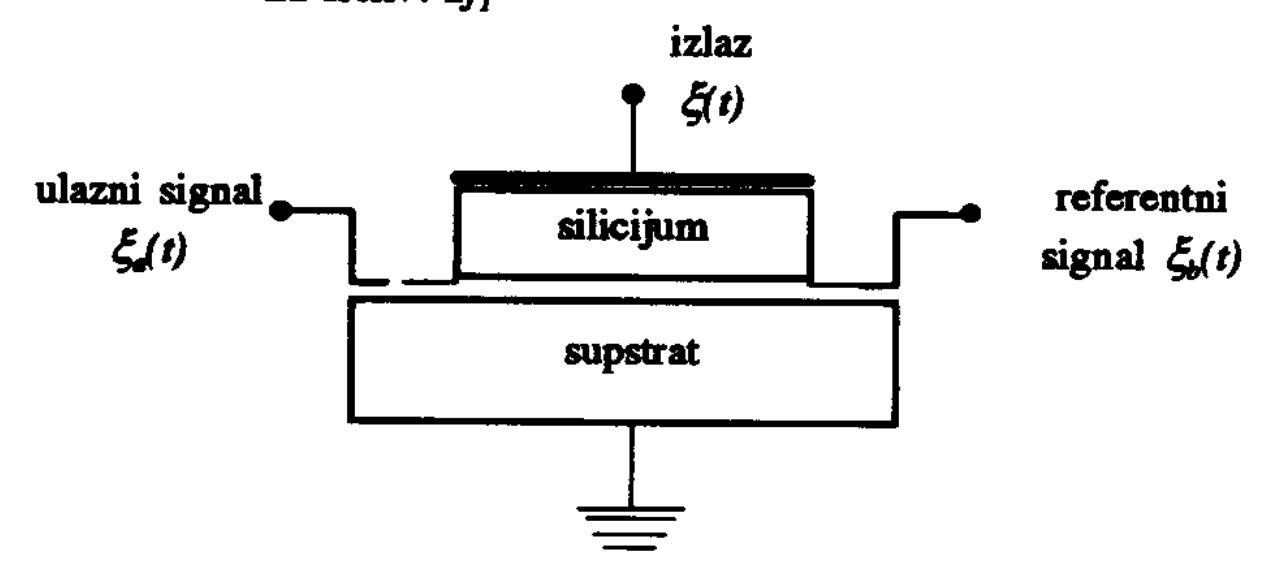

Sl. 14 - Osnovni elementi SAW konvolvera: $a$ - struktura, b-poprečni presek

klapaju, a zbog nelinearne interakcije električnog polja i potencijala na površini poluprovodnika pojavljuju se proizvodi mešanja. Za realizaciju konvolucije bitan je samo treći proizvod koji se stvara nelinearnošću drugog reda $\xi_{\mathrm{a}}(\mathrm{t}) \xi_{\mathrm{b}}(\mathrm{t})[1]$.

Ako se izvrši integracija na dužini $\mathrm{L}>10 \lambda_{0}\left(\lambda_{0}=\mathrm{v} / \mathrm{f}_{0}\right)$ za ukupni izraz biće bitan baš željeni treći proizvod. Kada se tako dobijeni signal propusti kroz detektor ovojnice dobija se [1]:

$$
\xi(t)=\int_{t-L / 2 v}^{t+L / 2 v} \xi_{a}(\tau) \xi_{b}(2 t-\tau) d \tau
$$

Za odabranu dužinu oblasti integracije $\mathrm{L}=\mathrm{Tv}$ prethodni izraz predstavlja konvoluciju ulaznih signala, uz napomenu da je izlazni signal komprimovan u vremenu za faktor 2 , a frekvencija signala na izlazu $\xi(t)$ dvostruko je viša. Fizički, to je posledica prostiranja akustičkih talasa u suprotnim smerovima, pa je njihova relativna brzina $2 \mathrm{v}$. Interval $\mathrm{T}$ zavisi od osobina supstrata, i prema trenutnim tehnološkim mogućnostima može iznositi do $100 \mu \mathrm{s}$.

Dinamički opseg programabilnih konvolvera ograničen je termičkim šumom za signale sa malom snagom, a za velike snage signala saturacijom u kristalu i varira od 30 do $50 \mathrm{~dB}$, zavisno od konfiguracije.

\section{Zaključak}

SAW komponente omogućavaju realizaciju niza funkcija obrade signala $u$ radarskim, sonarskim, komunikacionim $i$ sistemima EW. Male dimenzije, niska cena i mala potrošnja karakteristike su koje ih čine interesantnim za realizaciju 
kako vojnih tako i komercijalnih uređaja. Kompresija impulsa i njene mnogobrojne primene lako se postižu SAW linijama za kašnjenje i čirp-filterima. Značajna primena ovih komponenti jeste u sistemima za komunikaciju sa prenosom u proširenom spektru, gde se čitav niz funkcija (kompresija, sinhronizacija, detekcija prilagođenim ili razdešenim filterom, generisanje talasnih oblika) postiže SAW komponentama. Presretanje i detekcija signala u šrokom frekvencijskom opsegu, što je značajno u sistemima za protivelektronsku borbu, postiže se primenom SAW komponenti u kompresivnom prijemniku.
Literatura;

[1] Kostic, I. M.: Radiotehnicki sklopovi i arhitekture, Pergmena, Podgorica, 1996.

[2] Maines, J. D., Paige, E. G. S.: Surface-acoustic-wave components, devices and applications, Proc. IEE, IEE Reviews, Vol. 120, No.10R, October 1973, pp. 1078-1110.

[3] Jack, M. A., Grant, P. M., Collins, J. H.: The Theory, Design, and Applications of Surface Acoustic Fourier-Transform Processors, Proc. of the IEEE, Vol. 68, No. 4, April 1980 , pp. $450-468$.

[4] Martin, T. A.: The IMCON Pulse Compression Filter and its Applications, IEEE Trans. on microwave theory and techniques, vol. MTT-21, No. 4, April 1973, pp. 186-194.

[5] Grant, P. M., Morgan, D. P., Collins, J. H.: Generation and Correlation of Digitally Controlled Coherent FrequencyHopped Waveforms Using Surface Acoustic Wave Devices, Proc. of the IEEE, May 1976, pp. 826-828.

[6] Zejak, A. J.: Razdešni filtri u radarima sa fazno kodovanim signalom optimizovani po Doplerovom pomaku frekvencije, doktorska disertacija, Elektrotehnicki fakultet, Univerzitet u Beogradu, 1994.

[7] Shreve, W. R.: Signal Processing Using Surface Acoustic Waves, IEEE Communications Magazine, Vol. 23, No. 4, April 1985, pp. 6-11. 